1Fundação Oswaldo Cruz (Fiocruz), Escola Nacional de Saúde Pública Sergio Arouca (Ensp), Centro de Estudos da Saúde do Trabalhador e Ecologia Humana (Cesteh) - Rio de Janeiro (RJ), Brasil. gidborgess@gmail.com

\section{Comunidade Ampliada de Pesquisa em ambiente virtual (CAP on-line) sobre trabalho e saúde docente}

\author{
Expanded Community for Research in a virtual environment (CAP \\ on-line) on teacher work and health
}

Gideon Borges dos Santos', Kátia Reis de Souza', Andréa Maria dos Santos Rodrigues', Luciana Gomes', Eliana Guimarães Félix' ${ }^{\mathbf{1}}$ Luísa Maiola de Araujo', Jordânia Lira da Costa1

DOI: 10.1590/0103-1104202213217

RESUMO A pandemia do novo coronavírus afetou a dinâmica do cotidiano escolar, obrigando os(as) professores(as) a um movimento de adaptação para dar conta das demandas impostas pelo distanciamento social. Esse cenário também atingiu as pesquisas, cujas técnicas de coletas de dados se davam de maneira presencial e tiveram que ser realizadas remotamente. O objetivo deste texto é descrever a trajetória da Comunidade Ampliada de Pesquisa, adaptada para o ambiente virtual (CAP on-line), como parte da pesquisa que buscou examinar as novas exigências do ensino remoto e suas implicações para a saúde dos(as) professores(as). Foram realizadas três oficinas com a participação de professores(as) do Ensino Fundamental e Médio. Observou-se que o processo de pesquisa tem correlações com os próprios resultados do estudo, especialmente no que se refere aos novos aprendizados trazidos pelo ensino remoto. Conclui-se que o compartilhamento de experiências de trabalho por meio da CAP on-line é uma possibilidade. No entanto, o aperfeiçoamento nos modos de interação virtual, o domínio do aparato tecnológico e o acesso a equipamentos de qualidade são elementos a serem observados para o aperfeiçoamento dessa abordagem coletiva de investigação.

PALAVRAS-CHAVE Teletrabalho. Aprendizagem. Saúde do trabalhador.

\begin{abstract}
The new Coronavirus pandemic has affected the dynamics of everyday school life, forcing teachers to adapt to the demands imposed by social distancing. This scenario also involved the surveys, whose data collection techniques took place in person and had to be carried out remotely. This text aims to describe the trajectory of the expanded research community, adapted to the virtual format, as part of the research that sought to examine the new requirements of remote teaching and its implications for teachers' health. Three workshops were held with the participation of elementary and high school teachers. It was observed that the research process has correlations with the results of the study, especially concerning new learning brought by remote learning. It is concluded that sharing work experiences through online CAP is a possibility. However, the improvement in the modes of virtual interaction, mastery of the technological apparatus, and access to quality equipment are elements to be observed in order to improve this collective approach to investigation.
\end{abstract}

KEYWORDS Teleworking. Learning. Occupational health. 


\section{Introdução}

A pandemia do novo coronavírus que afetou a dinâmica do cotidiano escolar, exigindo dos(as) professores(as) um forte movimento de adaptação e criatividade para dar conta das demandas impostas pelo distanciamento social, também atingiu as pesquisas, na medida em que a coleta de dados, que se dava de maneira presencial, passou a ser realizada remotamente. $\mathrm{O}$ exemplo que será objeto desta reflexão é a experiência de pesquisa participativa que adotou como estratégia metodológica a Comunidade Ampliada de Pesquisa, adaptada para o ambiente virtual (CAP online), em decorrência das exigências impostas pela crise sanitária. De maneira equivalente à reinvenção do trabalho docente para garantir a continuidade das atividades escolares, o processo de pesquisa, cuja finalidade foi investigar exatamente as novas exigências do ensino remoto e suas implicações para a saúde dos(as) professores(as), também foi atingido pelas interferências e adversidades comuns aos sujeitos investigados, para dar conta dos novos modos de trabalhar. Além da precariedade de acesso à internet e do pouco conhecimento sobre o uso do aparato tecnológico, os modos de interação no ambiente virtual foram fatores concorrentes ao trabalho docente remoto, especialmente no que diz respeito às consequências para saúde dos(as) professores(as) e para formação dos(as) alunos(as), tal como o foram no processo de pesquisa.

Em geral, os(as) professores(as) tiveram que reaprender a utilizar didática e metodologicamente os recursos e as tecnologias disponíveis, de modo a dar continuidade às atividades escolares: reorganização do tempo de trabalho, gravação e edição de vídeos, distanciamento social dos(as) alunos(as), presença constante de pais e responsáveis nas aulas ministradas on-line são exemplos de mudanças sob as quais os(as) professores(as) tiveram que lidar e se adaptar ${ }^{1}$. Além disso, de forma ainda mais aguda, essas transformações ocorreram na privatividade do lar, um espaço que, desde a modernidade, quando o trabalho passou a ocupar a esfera social e pública ${ }^{2}$, esteve reservado à intimidade, ao lazer e ao ócio. Para Araújo e Lua ${ }^{3}$, o contexto da pandemia de Covid-19 transformou a casa em espaço de trabalho, e as demandas com cuidados infantis e familiares aumentaram ${ }^{4,5}$, embora a conciliação dos períodos de trabalho e dos cuidados da casa e da família sejam, reconhecidamente, velhos dilemas na vida das mulheres.

O processo de construção do estudo se deu em conjunto com o Sindicato dos Professores de Macaé e Região (Sinpro-Macaé), na perspectiva de uma investigação colaborativa, na qual potencializam-se os polos de conhecimento envolvidos, ou seja, aquele constituído pelas disciplinas científicas e o polo das experiências do trabalho, integrando saberes e práticas procedentes da ciência e do cotidiano laboral6. Pelo ângulo conceitual, Brito e Athayde ${ }^{7}$ asseguram que constituir uma CAP e desenvolvê-la diz respeito à experimentação de uma comunidade dialógica de pesquisa com a perspectiva de trabalhar, centralmente, com a experiência do próprio trabalho, ampliando a capacidade crítica e o olhar investigativo de todos os envolvidos. No que diz respeito à CAP on-line, as interações entre pesquisadores e participantes da pesquisa em ambiente digital possibilitam uma nova modalidade de construção coletiva do conhecimento, podendo efetivar novos padrões de pesquisa social de natureza qualitativa, ${ }^{5,8}$

$\mathrm{Na}$ CAP, valorizam-se a comunicação e o diálogo entre os participantes que pertencem a grupos homogêneos de trabalho ${ }^{6}$, ou seja, são membros da mesma comunidade que realizam atividades laborais semelhantes. Destarte, formalizam-se as experiências, colocando em análise os diferentes pontos de vista sobre o trabalho com foco na relação com a saúde.

Ademais, embora o diálogo em ambiente digital seja ampliado com relação ao tempo e ao espaço ${ }^{9}$, abrindo novas possibilidades de produção de conhecimento ${ }^{5}$, na prática, ocorrem perdas relacionais importantes, principalmente, no que diz respeito à percepção 
de expressões corporais. Há limites no que se refere ao campo de visão dos participantes, considerando que as telas de monitores e de artefatos tecnológicos permitem uma visualização limitada dos participantes, circunscrita a enquadramentos parciais daqueles que estão conectados.

Com o objetivo de descrever a trajetória e a organização da CAP on-line, pretende-se, neste texto, refletir sobre os desafios dessa abordagem de pesquisa em relação ao modo presencial e suas interfaces e correlações com os próprios resultados do estudo sobre trabalho e saúde docente, especialmente, no que se refere aos novos aprendizados da experiência docente no contexto da pandemia. Nesse processo, a Comunidade Ampliada de Pesquisa adaptada para o formato virtual constitui-se para além de uma escolha metodológica, parte da pesquisa que buscou também examinar as novas exigências do ensino remoto e suas implicações para a saúde dos(as) professores(as).

\section{A experiência da CAP on-line}

A concepção originária de CAP baseia-se nas experiências sindicais italianas de investigação dos processos de coanálise do trabalho e da saúde ${ }^{6}$. Nessa perspectiva, adota-se como princípio fundamental o trabalho como determinante social da saúde, e os trabalhadores como sujeitos da análise e da transformação dos ambientes de trabalho'. Complementarmente, um dos principais pressupostos teóricos no campo da saúde do trabalhador é o reconhecimento de que a saúde é fortemente influenciada pelo contexto histórico-social e pela capacidade organizativa e de resistência dos(as) trabalhadores(as), conforme preconizado pela Medicina Social Latino-Americana ${ }^{\mathbf{1 0}}$. Assim, configura-se uma relação orgânica com os movimentos sociais, sobretudo, com as organizações sindicais para defesa coletiva da saúde que, no contexto atual, tem-se materializado por meio dos ambientes virtuais ${ }^{11}$.
Em maio de 2020, iniciou-se uma sequência de diálogos entre o Sinpro-Macaé e pesquisadores do Centro de Estudos em Saúde do Trabalhador e Ecologia Humana (Cesteh/ Escola Nacional de Saúde Pública Sergio Arouca - Ensp/Fundação Oswaldo Cruz Fiocruz) com a finalidade de investigar a relação Saúde e Trabalho de Professores(as) da Rede Pública e Particular de Educação do Rio de Janeiro em Tempos de Pandemia e Pós-Pandemia.

Quanto à dinâmica adotada nas reuniões da CAP on-line, iniciou-se com a apresentação dos objetivos do trabalho e uma breve exposição, por parte do coordenador do projeto, dos objetivos da pesquisa. Adicionalmente, foi demandado que os participantes permanecessem com as câmeras abertas, de sorte que todos(as) se reconhecessem pelos nomes e faces, como uma comunidade em processo de formação. Em que pese o fato de as câmeras fechadas possibilitarem melhor conexão virtual, observou-se que o fechamento delas provoca interferência na experiência comunicativa e pedagógica.

Após apresentação, foi solicitado aos participantes que falassem sobre aspectos do processo de trabalho remoto e pontos específicos da organização laboral, a saber: ritmo do trabalho e das atividades; jornada de trabalho (a que horas começa e termina); pausas para descanso; conciliação entre trabalho docente e doméstico; relações hierárquicas com a gestão e coordenação escolar; relações entre colegas professores(as); formas de controle sobre o trabalho; sobrecarga de trabalho; dificuldades materiais e tecnológicas para consecução do trabalho; queixas de saúde e modos de resistências individuais e coletivas; descrição das aulas síncronas e assíncronas.

O número de participantes dos encontros foi variado. Na primeira reunião (18/07/2021), participaram 10 pessoas, sendo 3 professores(as), 5 pesquisadores(as) e 2 sindicalistas. No segundo encontro (25/07/21), estiveram presentes 2 professores(as), 5 pesquisadores(as) e 1 sindicalista. Quanto à terceira e última reunião 
(01/08/21), participaram 6 professores(as), 5 pesquisadores(as) e 2 sindicalistas. A divulgação da pesquisa foi feita no site do sindicato, em meios de comunicação na região de Macaé, e por meio de carta-convite encaminhada aos filiados. Todos os encontros foram gravados, transcritos; e o aceite ou a autorização dos participantes foram registrados oralmente, conforme termos do comitê de ética em pesquisa. Os dados obtidos foram analisados e posteriormente validados pela CAP on-line, entre os polos (sindicatos e pesquisadores) envolvidos.

O número de professores(as) nas reuniões possibilitou mais tempo de fala para cada participante, mais interações e diálogo, o que é desejável em grupos presenciais de caráter participativo ${ }^{12}$. Deve-se considerar ainda que o grupo em questão pertencia à rede particular de ensino, correndo risco de perda de emprego em função da exposição em redes digitais, algo que pode ter influenciado a baixa adesão, mesmo sendo a pesquisa um espaço protegido.

No que concerne à metodologia da CAP online, é importante considerá-la na perspectiva da antropologia participante e da etnografia. Para Brandão ${ }^{13}$, a antropologia contribui com algumas lições para a prática de pesquisa e da educação, como escutar atentamente o outro e compreender silêncios, entrelinhas, desvendar mistérios e compartilhar experiências. Na CAP on-line, procurou-se construir a simetria entre os polos do conhecimento envolvidos e a partilha de saberes por meio do reconhecimento do outro como igual ${ }^{14}$. Assim, um fundamento importante dessa perspectiva é que ela não se sustenta em ideias abstratas, pois o conhecimento sobre o trabalho apenas tem sentido na história real dos próprios trabalhadores. Já a etnografia, em sua forma básica, exige que o pesquisador submerja no mundo que estuda por um tempo determinado e leve em consideração as relações que se formam entre os participantes ${ }^{15}$. A etnografia virtual é um processo ainda experimental que se baseia em meios eletrônicos ${ }^{16}$.

Sobre os dias para realização da pesquisa, foi pactuado com o sindicato que seriam aos sábados, quando os(as) professores(as) estão de folga, embora cansados devido à longa jornada semanal, algo expressamente relatado por eles. Isso porque o processo de ensino passou (e ainda passa) por reformulações contínuas nos ambientes virtuais, exigindo criatividade e adaptações rápidas, na maioria das vezes de modo solitário, considerando que a experiência de ensino remoto está pouco formalizada e compartilhada entre os próprios docentes. Por certo, o ensino remoto em contexto pandêmico constitui-se como uma face do trabalho precarizado com ênfase no uso exaustivo de recursos tecnológicos ${ }^{11}$.

A rigor, pesquisas por meio de ambientes digitais ganham vigor desde o início dos anos $2000^{8,15}$, em parte, sob o argumento de uma suposta vantagem do baixo custo ${ }^{17}$, sem dimensionar os gastos para manutenção de internet (de boa qualidade) e substituição periódica de ferramentas tecnológicas, devida ao desgaste dos equipamentos. No entanto, essa prática se ampliou com as novas exigências de trabalho no contexto da pandemia, o que tornou possível compartilhar e avaliar experiências, no âmbito da própria CAP, com vistas ao aperfeiçoamento das abordagens coletivas de investigação social desenvolvidas no ciberespaço $0^{5,17}$. A pesquisa foi aprovada pelo Comitê de Ética em Pesquisa da Ensp (CAEE: 33455720.2.0000.5240).

\section{Novos aprendizados no trabalho docente}

O uso da tecnologia como recurso alternativo para realização da pesquisa sobre o trabalho docente remoto, em tempos de pandemia, foi o que, de fato, tornou possível, ainda que de forma adversa, o processo de coleta de dados. $\mathrm{O}$ trabalho remoto exigiu um novo aprendizado, e o que se observou é que as adversidades enfrentadas pelos(as) professores(as) durante a realização de suas atividades de trabalho também foram aquelas evidenciadas na realização da CAP on-line: atrasos no início do processo de coleta de dados porque os(as) 
professores(as) não conseguiam acesso à plataforma ou mesmo configurar áudio e vídeo para sua utilização adequada; qualidade de internet, do computador, celular ou tablet utilizados que exigiam interrupções das falas; interrupções da entrevista por causa problemas técnicos; atenção dividida entre a participação nas entrevistas e a atenção aos filhos, familiares ou aos afazeres domésticos de modo geral; ruídos externos ao ambiente virtual, sejam decorrentes da própria residência ou de algum carro de alto-falante de anúncios que importunavam o desenvolvimento da atividade. Todas as perturbações externas e constrangimentos durante as reuniões também podem ser compreendidos pelas particularidades do trabalho remoto que entrelaça a vida doméstica e o trabalho docente.

Chamou-se atenção às atividades que causavam grandes desconforto aos professores(as), por exemplo, a experiência da câmera desligada pelos(as) alunos(as) no momento da realização das aulas e a gravação de vídeos. O fechamento das câmeras, algo bastante comum nas aulas síncronas, provocava nos(as) professores(as) uma sensação de baixa interatividade e isolamento.

Uma outra coisa que eu sinto que dificultou muito o nosso trabalho é essa coisa de estarmos praticamente isolados, não tem como trocar ideia de como está fazendo. (Professor do Ensino Médio).

Essa 'inabilidade' em ministrar aula sem poder ver os(as) alunos(as) causa desconforto, e foi curioso observar como a experiência da câmera desligada provocava no professor, que tinha o controle da fala, um vazio de presença. A experiência estética de estar próximo do outro, observar a sua expressão corporal, perceberem-se uns aos outros, suas reações, olhares e interagirem entre si foi pouco dimensionada. Em situação de trabalho remoto, a ausência da imagem do outro, quando a câmera está desligada, algo que também pode ser considerado uma forma de negação da presença, às vezes encoberta por um problema técnico de conexão ou simplesmente porque na hora da aula o(a) aluno(a) está desenvolvendo atividades paralelas, provoca nos(as) professores(as) uma sensação de não estar interagindo com um sujeito encarnado, como se houvesse uma suspensão dos laços com a realidade social, com a história e com o corpo ${ }^{18}$. Na experiência da CAP, era recorrente o(a) moderador(a) solicitar aos(às) professores(as) que abrissem a câmera, algo que era feito sem resistências, contudo, por um intervalo de tempo suficiente para apresentação uns dos outros. Importa considerar que a experiência do(a) moderador(a) durante o diálogo com os participantes foi coincidente com a experiência verbalizada por professores(as) sobre a câmera desligada dos(as) alunos(as): baixa interatividade.

Outro desafio enfrentado por professores(as) no período de realização do trabalho remoto e, também, reproduzido na realização da CAP on-line sobre o trabalho docente foi a impossibilidade de antecipar as ocorrências do trabalho, exigindo dos trabalhadores imaginar novas soluções e resultados ${ }^{19}$. Por tratar-se de um grupo de trabalhadores que sempre desenvolveu suas atividades de modo predominantemente presencial, o desconhecimento técnico no uso dos aparelhos tecnológicos, aplicativos e plataformas consistiu em um desafio para muitos(as) professores(as). No entanto, a experiência de gravar um vídeo foi aquela que causou em alguns(mas) deles(as) maior desconforto. $\mathrm{O}$ 'medo de câmera' é um sentimento que a área da comunicação social tem bastante interesse em tomar como objeto de estudo.

Você tá só: você e a câmera. Não tem ninguém. Bate uma vergonha! Não sei por que... me dá tremedeira por dentro... eu dano a suar. Eu gravo vídeo com toalhinha no colo. $E$ [me] seco. E fico num nervoso... você gagueja... Esquece o texto que você tinha preparado... Além do trabalho mecânico, você tem que ter toda uma preparação psicológica. (Professora do segmento I). 
Em tese de doutoramento sobre a participação dos(as) professores(as) universitários(as) na produção de vídeos educacionais, Cabral Júnior ${ }^{20}$ observa o estranhamento desses profissionais quando lhes são solicitadas aulas gravadas em vídeo. O medo de errar foi a manifestação mais comum entre professores(as) ante a câmera de vídeo. Entre algumas razões, a preocupação quanto ao resultado do material gravado, não transmitir credibilidade para o(a) aluno(a), falar alguma bobagem ou mesmo falar incorretamente fazem com que, diante da câmera, os(as) professores(as) sintam-se intimidado(as), travado(as), e reajam com gagueira, paralisia e suor ${ }^{20}$. A ausência do interlocutor e, consequentemente, todos os sinais emitidos pela presença do corpo que são capazes de transmitir mensagens, associado à falta e conhecimento prático sobre a gravação dos vídeos, podem influenciar o medo dos(as) professores(as) na realização dessa atividades que, no trabalho remoto, tornou-se bastante comum.

Os(as) próprios(as) professores(as) relataram preferir as aulas síncronas, aquelas que ocorrem em tempo real, por meio de plataformas, do que a gravação de um vídeo. A razão está no poder de interação que essas aulas permitem em relação aos vídeos previamente gravados, a despeito das câmeras desligadas configurarem um incômodo na atividade.

Eu falo pra você que eu prefiro mil vezes que tivesse que fazer lives ao invés de gravar os vídeos. Eu acho que flui. Há uma troca. O que a criança não está entendendo, ela está falando ali na hora.. tirando as dúvidas e ali a gente vai trabalhando.. $E$ eu vejo as coisas funcionarem. Diferentemente de quando gravo os vídeos e às vezes não tenho retorno. (Professora $\mathrm{A}$ - segmento I).

A formação humana é um fenômeno que se dá 'diretamente entre os homens' para lembrar uma expressão da Hannah Arendt ${ }^{2}$. De fato, a 'solidão interativa' das aulas remotas transforma os sujeitos da experiência pedagógica em 'agentes impessoais'18, parecendo exigir maior esforço (ao menos uma nova competência) por parte dos(as) professores(as), no sentido de convocar a presença dos(as) alunos(as) para aprendizagem.

Esse retorno não é imediato e mesmo ele não sendo imediato, uma coisa quem me desgasta muito, eu fico ali atento querendo saber se o aluno tá acompanhando o que foi postado, se tem alguma dúvida e é silêncio total e isso desgasta muito comigo, as vezes eu fico sem almoço, vou direto [...] é na semana seguinte que eles vão entrar em contato se tem uma dúvida e ainda é muito pouco. (Professor Ensino Médio).

Evidentemente, essa característica ganha força porque está-se falando de professores(as) que construíram seu repertório profissional em aulas presenciais com pouco ou nenhuma experiência em ensino remoto. Talvez, o efeito mais consequente nessa expectativa que não se cumpre, a de obter retorno dos(as) alunos(as), esteja no desgaste que o ensino remoto tem provocado nos(as) professores(as) quando comparado ao presencial, algo sinalizado pelos(as) participantes, quando recorrem ao adjetivo 'desgastante' para caracterizar o seu trabalho.

Ao trabalho remoto, é atribuído um esgotamento físico e mental maior se comparado ao momento presencial. Além de uma nova maneira de trabalhar que exige novos recursos e aprendizagens, ele produz a sensação de estar sempre conectado, já que, a qualquer momento, o trabalhador é convocado a responder uma mensagem, a um e-mail, ou atender a alguma demanda relativa ao trabalho.

Ao final de uma aula de 40 minutos parece que eu trabalhei a semana inteira. (Professor do Ensino Médio).

Jornada de trabalho aumentou e sobrecarregou, antes eu trabalhava 3 dias e agora eu me vejo trabalhando a todo dia procurando videozinho. (Professor do Ensino Médio).

Parece correto afirmar que ocorrem perdas de demarcações temporais, já que o(a) 
professor(a) permanece à disposição dos(as) alunos(as) mesmo após o horário de trabalho. Assim, a presença virtual do(a) professor(a) perdura em qualquer horário do dia, principalmente de forma assíncrona, seja pelas mensagens nos aplicativos de celulares ou nas plataformas das salas de aulas virtuais, como na ferramenta Classroom. Essa nova configuração do trabalho docente leva a queixas de saúde, como ansiedade, estresse, alterações no padrão do sono, dores de cabeça e coluna com o uso abusivo de analgésicos ${ }^{11}$.

A aquisição do conhecimento técnico no uso dos aparelhos e softwares, no trabalho remoto, foi uma experiência bastante difícil para os(as) professores(as), pelo tempo curto e a forma abrupta que eles tiveram para adquiri-la, na medida em que a conversão das aulas presenciais para o ensino remoto não foi gradual. A ausência de capacitação para utilizar os recursos disponíveis e viáveis ao trabalho remoto também fez com que a aprendizagem desses processos fosse mais lenta e ainda insuficiente para potencializar as atividades de trabalho.

Observa-se também nesse contexto uma intensificação do trabalho, não apenas porque houve aumento quantitativo da jornada de trabalho, passando de três dias para a semana inteira, como também criou uma sensação de maior esgotamento mesmo quando as aulas são de 40 minutos. Esse desgaste do trabalho docente remoto foi percebido não apenas entre professores(as), mas também entre alunos(as), que se queixam de um esgotamento das atividades on-line.

De fato, o trabalho remoto é uma adaptação ao trabalho presencial a ser realizado em um tempo determinado. Outrossim, a despeito do aceleramento no uso das tecnologias educacionais com o advento da pandemia, algo que tende a se intensificar, mesmo após o retorno às atividades educacionais presenciais, há uma expectativa dos(as) professores(as) em retomar as atividades 'normais' tão logo seja possível, considerando que o trabalho remoto é, na concepção deles(as), pela própria natureza de ser 'adaptado', menos potente à formação dos(as) alunos(as) perante o ensino presencial, na medida em que as experiências educacionais ficam sobremaneira limitadas.

O trabalho remoto trouxe também como exigência um novo aprendizado em relação à própria jornada de trabalho, além daqueles relacionados com o uso dos novos equipamentos, modos de ensino, interação com alunos, entre outros. Trata-se da organização da jornada de trabalho, na qual os(as) professores(as) se veem obrigados(as) a trabalhar a qualquer momento, quando demandados(as) pelos(as) alunos(as) ou pela coordenação ou direção da escola, ou ainda quando pretendem planejar as suas aulas.

[...] a recriação de rotina pede da gente... demanda da gente um equilíbrio emocional, um equilíbrio de trabalho. Essas habilidades que antes não eram tão demandadas [...]. Agora eu não tenho um horário de início e fim, um lugar... Eu tô no mesmo lugar e eu que tenho que reorganizar todos esses horários. (Professor do Ensino Médio).

Ocorre que, no trabalho presencial, esse controle da jornada de trabalho é, de certa forma, organizado pela dinâmica da rotina da escola: início das aulas, intervalo, término. Como a experiência do trabalho remoto é algo relativamente recente, o controle na organização do tempo, algo que o(a) professor(a) ainda precisa construir, sob pena de trabalhar além da jornada formal, fica descontrolado, causando maior desgaste docente. A questão mais grave é a imposição desse limite que recai sobre o indivíduo, desobrigando as instituições de estabelecer compromissos com a organização do trabalho e com a saúde do trabalhador.

Esse isolamento é, inclusive, observado pelos(as) professores(as) pesquisados(as), ao fazer referência ao desenvolvimento das suas atividades, seja porque foi necessário reinventar o ensino do ponto de vista didático metodológico do formato presencial para o remoto, sem o treinamento adequado - muitos(as) professores(as) observaram tê-lo 'aprendido' sozinho(a) -, seja na realização do trabalho sem o convívio com os(as) colegas. 
Tivemos que aprender da noite pro dia... editar, gravar, tudo... sem suporte. Não temos plataforma também. (Professora B - segmento I).

A gente tá aí sozinho, se virando como pode, pra conseguir executar esse trabalho. (Professor A do Ensino Médio).

Uma outra coisa que eu sinto que dificultou muito o nosso trabalho é essa coisa de estarmos praticamente isolados, não tem como trocar ideia de como está fazendo. (Professor B do Ensino Médio).

A exigência de novos aprendizados vai desde o uso técnico dos equipamentos até uma nova experiência estética, especialmente para gerações cuja tecnologia, enquanto mediadora das relações sociais, nunca foi uma trivialidade. Aprender, portanto, a se relacionar e, inclusive, a estabelecer processos democráticos em ambientes virtuais torna-se uma questão premente na medida em que o tipo de relação em ambientes virtuais termina por reproduzir as relações dos ambientes não virtuais.

\section{Reflexões sobre a experimentação da CAP on-line}

A experimentação da CAP na modalidade on-line representou um grande desafio para a equipe de pesquisa pelo seu ineditismo. Até então, todas as experiências do grupo de aplicação desse dispositivo, em diferentes categorias profissionais, foram presenciais. A necessidade, portanto, de adequar todo o processo de constituição e desenvolvimento da CAP ao modo remoto colocava-se como a única forma possível no momento da pandemia de Covid-19. Foi preciso repensar as estratégias de comunicação para convidar professores(as) a participar. Entender que dia da semana e período teriam maior adesão e, sobretudo, definir metodologicamente como poderiam ser os encontros, de forma que se constituíssem, de fato, em espaços de diálogos e de produção de conhecimento entre os diferentes polos de saberes, visando repensar as situações de trabalho ${ }^{\mathbf{1 4}, 21}$.

Um primeiro aspecto a ser considerado diz respeito à utilização das tecnologias como mediadoras na comunicação para a CAP on-line, uma evidência dos desafios e limitações. De acordo com Bailenson ${ }^{22}$, a relação em plataformas digitais tende a ser mais exaustiva do que nos encontros presenciais, além de alterar o modo de comunicação. $\mathrm{O}$ autor sugere que a posição frontal em que se fica durante as conversas virtuais simula um intenso contato visual com diversas pessoas, ao mesmo tempo, sem que se possa desviar os olhares do mesmo modo que ocorreria no contato face a face. Durante os encontros virtuais, observaram-se alguns(mas) docentes que se posicionavam de outros modos ou em lugares escuros, estabelecendo assim outras formas de desenvolver o diálogo no contexto virtual que acabaram por não priorizar a simulação do contato visual.

Ainda baseado nas hipóteses de Bailenson ${ }^{22}$, há um aumento na carga cognitiva nos encontros virtuais devido à comunicação não verbal ocorrer de forma diferente das conversas presenciais. Isto ocorre em razão da impossibilidade de expressão com todo o corpo, o que leva a um aumento do foco da comunicação emitida do pescoço para cima. Do mesmo modo, há uma maior dificuldade de significação das pistas não verbais emitidas, visto que movimentos de olhos e de cabeça, por exemplo, podem ser motivados por algo que está fora da visão dos demais. Tendo em vista que a maioria dos participantes se encontravam em casa, e, também, para evitar ruídos e interferências nas falas, os microfones permaneciam fechados, abrindo-os somente quando o interlocutor fosse falar - há que se considerar que os sons de cada ambiente também poderiam produzir reações não verbais difíceis de ser interpretadas pelos outros participantes.

Um exemplo é a necessidade de controle das inscrições que é previamente determinada ou feita por meio de sinalizações, como 'levantar 
a mão' ou pelo recurso 'bate-papo'. Suspeita-se que isso iniba certo grau de espontaneidade, bem como de interação entre os participantes. A qualidade do sinal de internet também acaba impactando na interação, mediante interrupções momentâneas, 'congelamentos', que podem atrapalhar a recepção ou o envio da fala, por exemplo. Quando isso ocorre com certa frequência, pode levar à irritação em decorrência da frustração em não conseguir se comunicar. Essas, entre outras, características desse modelo de comunicação devem ser consideradas ao pensar no formato on-line da CAP, posto que interferem na forma com que as falas são mobilizadas no contexto virtual e, consequentemente, o modo em que se dá o diálogo entre os diferentes polos dos saberes ${ }^{23}$.

A construção da CAP on-line também suscita questionamentos sobre o risco de reprodução de uma lógica social excludente, uma vez que, no Brasil, uma em cada quatro pessoas não faz uso da internet ${ }^{24}$ e nem todas que a utilizam possuem as mesmas habilidades digitais. Dessa forma, a exclusão a partir do uso das tecnologias para a comunicação não está relacionada somente com o acesso à internet, mas também engloba questões referentes à distribuição desigual de recursos virtuais e os diferentes modos de apropriação das habilidades tecnológicas ${ }^{25}$.

Diante do exposto até aqui, a dúvida acerca da viabilidade do uso do dispositivo da CAP por meio de videoconferência está posta. Seria possível estabelecer uma relação entre os(as) participantes de modo que se sentissem à vontade para interagir e estabelecer uma dialogicidade, mesmo diante de todas as limitações desse modo virtual? Seria possível colocar o trabalho real em debate? Por outro lado, considera-se que o próprio conceito de "comunidade científica alargada" de Ivar Oddone 26(99), que inaugurou essa tradição e serviu de inspiração para tantos pesquisadores, ao longo do tempo, foi sofrendo mudanças na sua concepção e aplicação, de acordo com o momento histórico e as disciplinas que lhe utilizaram. Ocorre que mais uma vez essa ferramenta precisa passar por ajustes, agora referentes ao meio on-line. Vale lembrar que o conceito de CAP foi formulado, no Brasil, por Jussara Brito e Milton Athayde a partir de experiências no âmbito do Programa de Formação em Saúde, Gênero e Trabalho em Escolas, a partir dos anos 20007. Ainda assim, embora tenha se desenvolvido inspirado no conceito de comunidade científica alarga$\mathrm{da}^{6}$, incorporou também a perspectiva dos estudos de gênero ${ }^{7}$, da ergologia ${ }^{19,21,23} \mathrm{e} \mathrm{da}$ educação popular'12.

Ao longo desse processo, observou-se neste trabalho comum avanços nas reflexões sobre o fazer técnico dos(as) docentes no ensino remoto, o quanto eles mobilizaram o uso de si para confrontar os desafios, as implicações sobre sua saúde e as estratégias de enfrentamento individuais e coletivas acionadas. Obteve-se retorno do sindicato, visto que, já nessa fase inicial, os(as) professores(as) revelaram satisfação em poder ter um espaço para discutir o seu trabalho e a relação com a saúde, sinalizando interesse em prosseguir nesse processo, pois perceberam que repercutiu positivamente na sua saúde. $\mathrm{O}$ espaço da CAP foi essencial para (re)tratar coletivamente aspectos referentes à adequação do ensino remoto. Colocar os pontos em debate permite repensá-los e ressignificá-los. Conforme Mailliot e Durrive ${ }^{27}$, verifica-se que essa ferramenta gera ao mesmo tempo efeitos sobre a produção de conhecimento e sobre a gestão das situações de trabalho, provocando efeitos recíprocos entre o campo científico e o campo da gestão do trabalho.

Já a relação com os(as) sindicalistas também caminhou no sentido de incluir outros sindicatos e federações ao escopo da pesquisa. Em paralelo, eles(as) têm demonstrado interesse em seguir aprofundando as suas reflexões no espaço acadêmico, inclusive para repensar as ações sindicais, o que demonstra o quanto o dialogismo foi capaz de convocar certa motricidade de fluxos de diálogos internos e externos sobre a atividade de trabalho ${ }^{\mathbf{2 8}}$ estimulando os debates, as análises e as ações. 


\section{Conclusões}

A pesquisa possibilitou refletir que os desafios postos para a CAP on-line é bem similar aos encontrados pelos(as) professores(as) na adequação da sua prática docente presencial para remota: a mudança da interação social que antes era física e agora segue mediada pelas telas de celulares e computadores; a necessidade de saber manejar as demandas profissionais e domésticas; o olhar mais atento para os agravamentos decorrentes de jornadas de trabalho excessivas. Por outro lado, pesquisadores(as) e pesquisados(as) se deparam com novos aprendizados e reinventam-se para dar conta das novas exigências do trabalho, como enfrentamento do momento pandêmico.

Nesse sentido, há que se considerar vantagens e desvantagens dessa modalidade de pesquisa, em diálogo com a literatura e com os registros de diários de campo virtual. Com relação às desvantagens, observaram-se aspectos importantes no que diz respeito às dificuldades de uso das tecnologias, com destaque para a falta de habilidade dos participantes em usar a internet e as plataformas digitais, bem como a pouca experiência dos(as) moderadores(as), com coordenação de grupos on-line, de modo a contornar a falta de interação face a face. Importa considerar, ainda, a questão do acesso à internet, limitado para a maioria, e as adversidades das próprias redes. Ademais, corre-se o risco da superficialidade dos dados pela velocidade das discussões. Assim, deve-se estimular o diálogo em contexto de fala livre, pois, no ambiente on-line, também existem formas de coerção e restrições. Por certo, no ambiente virtual, pode-se recriar microrrelações de poder e subordinação. Na modalidade de pesquisa on-line, há invasão de privacidade dos(as) trabalhadores(as), tanto pesquisadores(as) quanto docentes participantes do estudo, expondo suas casas e ambientes familiares. Além disso, há a necessidade de adaptação dos postos de trabalho, em casa, com mobiliários e instrumentos que deveriam ser adequados, do ponto de vista ergonômico e da saúde (mesas, cadeiras, protetores de telas, fones especiais, entre outros), tanto para alunos(as) quanto para professores(as), algo que não foi proporcionado pelas escolas.

O principal aspecto positivo consiste, precisamente, na superação das barreiras geográficas, rapidez na coleta de dados e maior abrangência, uma vez que é possível encontrar pessoas de diferentes locais de forma simultânea, sem a necessidade de deslocamento espacial. O ambiente virtual permitiu a participação, na CAP on-line, de professores(as) que residiam em outros municípios do estado do Rio de Janeiro. Também foi possível criar um espaço de encontro e de diálogo que propiciou a reflexão sobre o trabalho docente em tempos de pandemia. Em geral, reuniões realizadas de forma síncrona podem ficar registradas e guardadas, permitindo o retorno à gravação multimídia em qualquer momento de modo a analisar duração, ritmo das intervenções, interações e dinâmica empreendidas.

Conclui-se pela potencialidade de compartilhamento de experiências de trabalho por meio da CAP on-line, contudo, o aperfeiçoamento nos modos de interação virtuais, o melhor domínio do aparato tecnológico e o acesso a equipamentos de qualidade são elementos a serem observados para aperfeiçoamento dessa abordagem coletiva de investigação. Outrossim, apesar das limitações relacionadas com a comunicação do meio digital, a CAP foi constituída, e as circulações entre os diferentes saberes ocorreram. Tanto a equipe de pesquisa adquiriu mais elementos que permitiram avançar nos (re) questionamentos, nos procedimentos, nos métodos e possibilidades dessa experiência de trabalho ${ }^{21}$, quanto os(as) professores(as) participantes reconheceram os saberes do trabalho dos quais são portadores. Todos(as) valorizaram a troca de experiência do cotidiano laboral que o distanciamento social imposto pela pandemia não foi capaz de construir. 


\section{Colaboradores}

Santos GB (0000-0003-1179-9404)*, Rodrigues AMS (0000-0001-8254-341X)* e Félix EG (0000-0002-3548-1356)* contribuíram para aquisição, análise e interpretação de dados para o trabalho, revisão e aprovação final da versão a ser publicada. Souza KR (0000-00022084-2606)* contribuiu para concepção, levantamento e análise dos dados, participação na elaboração do texto e aprovação da versão final a ser publicada. Gomes L (0000-00032038-0859)* contribuiu para concepção, delineamento do estudo, aquisição, análise e interpretação de dados para o trabalho, revisão e aprovação final da versão a ser publicada. Araujo LM (0000-0003-1573-3402)* contribuiu para concepção e delineamento do estudo. Costa JL (0000-0002-2233-5704)* contribuiu para análise e interpretação dos dados para o trabalho, revisão e aprovação final da versão a ser publicada.

\section{Referências}

1. Souza KR, Rodrigues AMS, Santos MBM, et al. Oficinas em saúde do trabalhador: ação educativa e produção dialógica de conhecimento sobre trabalho docente em universidade pública. Rev. Bras. Saude Ocup. 2020; 45(e4):1-9.

2. Arendt H. A condição humana. Rio de Janeiro: Forense Universitária; 2016.

3. Araújo TM, Lua I. O trabalho mudou-se para casa: trabalho remoto no contexto da pandemia de Covid-19. Rev. Bras. Saude Ocup. 2021; 46(e27):1-11.

4. Noveli M. Do off-line para o on-line: a netnografia como um método de pesquisa ou o que pode acontecer quando tentamos levar a etnografia para a inand Contributor ID)
5. Mendes CM. A pesquisa on-line: potencialidades da pesquisa qualitativa no ambiente virtual. Hipertextus. 2009; (2):1-9.

6. Oddone I, Marri G, Gloria S, et al. Ambiente de trabalho: a luta dos trabalhadores pela saúde. In: Souza KR, Masson L, Bonfatti RJ, et al., organizadores. Ambiente de trabalho: a luta dos trabalhadores pela saúde. 2 . ed. ampl. rev. São Paulo: Hucitec; 2020. 298 p.

7. Brito J, Athayde M. Trabalho, educação e saúde: o ponto de vista enigmático da atividade. Trab. Educ. Saúde, 2003; 1(2):239-266.

8. Santos TS. Do artesanato intelectual ao contexto virtual: ferramentas metodológicas para a pesquisa social. Sociologias. 2009; 11(21):120-156. 
9. Deslandes S, Coutinho T. Pesquisa social em ambientes digitais em tempos de COVID-19: notas teórico-metodológicas. Cad. Saúde Pública, 2020; 36(11):1-11.

10. Laurell AC, Noriega M. Processo de produção e saúde: trabalho e desgaste operário. São Paulo: Hucitec; 1989.

11. Souza KR, Santos GB, Rodrigues AMS, et al. Trabalho remoto, saúde docente e greve virtual em cenário de pandemia. Trab. Educ. Saúde. 2021; (19):1-14.

12. Freire P. Pedagogia do Oprimido. Rio de Janeiro: Paz e Terra; 2014.

13. Brandão CR. A pergunta a várias mãos: a experiência da pesquisa no trabalho do educador. São Paulo: Cortez; 2003.

14. Silva AA, Souza KR. Educação, pesquisa participante e saúde: as ideias de Carlos Rodrigues Brandão. Trab. Educ. Saúde. 2014; 12(3):519-539.

15. Hine C. Virtual Ethnography. London: Sage; 2000.

16. Amaral A, Natal G, Viana L. Netnografia como aporte metodológico da pesquisa em comunicação digital. Rev. sessões imag. Cin. Cibercult. Tec. Imag. 2008; (35):34-40.

17. Mercado LP. Pesquisa qualitativa on-line: utilizando a etnografia virtual. Rev. Teias, 2012; 13(30):169-183.

18. Valle L, Bohadana E. Sobre interatividade: do neologismo à construção do conceito. In: Valle L, organizadora. Filosofia da Educação a distância: conceitos e concepções. Curitiba: Appris Editora; 2017.

19. Schwartz Y, Durrive L. Vocabulário de Ergologia. In: Schwartz Y, Durrive L. Trabalho e ergologia II: diálogos sobre a atividade humana. Belo Horizonte: Fabrefactum; 2015. p. 375-386.

20. Cabral Junior PAF. Estratégias de produção audiovisual e seus reflexos sobre a participação do professor universitário na produção de vídeos educacio- nais. [tese]. [Porto Alegre]: Universidade Federal do Rio Grande do Sul; 2016.

21. Schwartz Y. A comunidade científica ampliada e o regime de produção de saberes. Trab. Educ. 2000; (7):38-46.

22. Bailenson JN. Nonverbal Overload: a theoretical argument for the causes of zoom fatigue. Technology, Mind and Behavior. 2021; 2(1).

23. Schwartz Y, Durrive L. Esquema geral do dispositivo a três polos. In: Schwartz Y, Durrive L. Trabalho e ergologia II: diálogos sobre a atividade humana. Belo Horizonte: Fabrefactum; 2015. p. 375-389.

24. Instituto Brasileiro de Geografia e Estatística. Acesso à internet e à televisão e posse de telefone móvel celular para uso pessoal 2018. Rio de janeiro: IBGE; 2020. [acesso em 2021 jun 12]. Disponível em: https:// biblioteca.ibge.gov.br/visualizacao/livros/liv101705_ informativo.pdf.

25. Senne F, Portilho L, Storino F, et al. A inclusão desigual: uma análise da trajetória das desigualdades de acesso, uso e apropriação da internet no Brasil. Rev. Direito Est. Telecom. 2020; 12(2):187-211.

26. Oddone I. La communauté scientifique élargie. Revue Societé Française. 1984; (10):28-33.

27. Mailliot S, Durrive L. Dialógo 3: a ergologia e a produção de saberes sobre os ofícios. In: Schwartz Y, Durrive L. Trabalho e ergologia II: diálogos sobre a atividade humana. Belo Horizonte: Fabrefactum; 2015. p. 151-240.

28. Souto AP, Lima KMNM, Osório C. Reflexões sobre a metodologia da clínica da atividade: diálogo e criação no meio de trabalho. Laboreal. 2015; 11(1):11-22.

Recebido em 16/08/2021

Aprovado em 12/11/2021

Conflito de interesses: inexistente

Suporte financeiro: o presente trabalho foi realizado com apoio da Coordenacão de Aperfeicoamento de Pessoal de Nível Superior Brasil (Capes) - Código de Financiamento 001 